\title{
Research on the Industrial Competitiveness of Service Outsourcing Industry in Hangzhou
}

\author{
Wang Zongguang ${ }^{1, \text { a }}$, Li Xinrui ${ }^{2}{ }^{\text {,* }}$

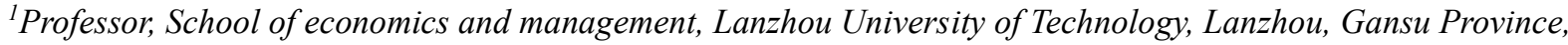 \\ China \\ ${ }^{2}$ Graduate student, School of economics and management, Lanzhou University of Technology, Lanzhou, Gansu \\ Province, China \\ a1966544907@qq.com \\ b*305120993@qq.com
}

\begin{abstract}
In recent years, with the acceleration of the international industrial transfer, service trade increasingly rises, the Hangzhou service outsourcing market has resulted in new growth opportunities. This paper uses relevant theories and empirical research to construct the evaluation system: Firstly, we select eight indicators from four aspects, using the factor analysis method to evaluate service outsourcing industry competitiveness. Secondly, by measuring the competitiveness of some cities in the Yangtze River Delta, Pearl River Delta and Beijing-Tianjin-Hebei region, we analyze the current development status of this industry in Hangzhou. At last, this paper puts forward some Suggestions on the development of service outsourcing industry in Hangzhou from four aspects: market development, intellectual property protection, human resource reserve and business environment.
\end{abstract}

Keywords: Service outsourcing, Factor analysis, competitiveness level

\section{杭州市服务外包业产业竞争力研究}

\author{
王宗光 ${ }^{1, a}$ 李欣莴 $2, b^{*}$
}

1 兰州理工大学经济管理学院教授, 兰州, 甘肃, 中国

2 兰州理工大学经济管理学院研究生, 兰州, 甘肃, 中国

1966544907@qq.com

b*305120993@qq.com

\section{摘要}

近几年，随着国际产业的加速转移，服务贸易日渐兴起，使得杭州市服务外包市场迎来新的增长机会。本文通 过利用相关理论、实证研究来进行构建评价体系: 首先从四个方面选取 8 个指标, 运用因子分析法对服务外包 产业竞争力进行评价, 其次通过测度长三角、珠三角、京津翼地区部分城市竞争力，对比分析杭州市该产业现 阶段的发展状况，最后基于市场开拓、知识产权保护、人力资源储备、商业环境这四方面提出改进建议。

关键词：服务外包，因子分析，竞争力水平

\section{1. 前言}

现代信息技术的发展大大促进了全球贸易的快 速扩张, 也使得大范围的全球服务贸易由不可能变为 可能，打破了原有服务产品 “不可贸易” 的特征，这
为企业发展尤其是跨国企业发展带来了诸多可能性。 服务贸易的产生让企业拥有了突破传统企业管理边 界的机会，企业将服务业中自身业务产品或业务管理 一部分外包出去，由第三方完成，这并不同于制造外 包，而是一种更 “高级”的对于企业的业务重组和流 
程再造，使得企业能够紧跟 “产业结构非实物化”、 “生产工序片段化” 的浪潮, 以更好的专注于核心业 务, 更好的实现企业经营目标。

近些年来通讯、计算机和信息服务等新型现代服 务业增长势头尤为突出, 加上经济全球化发展的不可 逆趋势以及国际产业的快速转移, 促使服务外包产业 在服务贸易经济中的比重不断提高。在以服务业为调 整目标的新一轮国际产业结构调整浪潮中, 中国由于 具备成本优势也迅速进入到了国际产业调整的另一 个承接过程一一服务外包。根据商务部公布的数据显 示, 2019 年中国企业承接服务外包合同额 15699.1 亿 元人民币, 执行额 10695.7 亿元, 同比分别增长 $18.6 \%$ 和 $11.5 \%$ 。同时我国服务外包产业结构也在进一步 地优化, 2019 年中国企业承接离岸信息技术外包执行 额 2894.3 亿元, 承接离岸业务流程外包执行额 1183.9 亿元, 承接离岸知识流程外包执行额 2477.6 亿元。由此从我国服务外包产业的发展趋势来看, 离 岸外包经济已逐渐成为推动我国对外贸易发展的重 要引擎。面向未来, 进一步扩大服务外包产业规模, 加快服务外包产业结构升级, 提高服务外包业务承接 质量已经成为国家的重点关注事项。杭州市作为中国 首批服务外包示范城市, 更应该起到模范带头作用, 利用自身优势, 响应国家号召, 积极发展服务外包产 业。

\section{2. 杭州市服务外包业产业发展现状}

2009 年国务院办公厅下发了《关于促进服务外包 产业发展问题的复函》, 将全国 20 个城市确认为中国 服务外包示范城市, 杭州市以其较好的服务外包产业 发展基础成为首批服务外包示范城市之一, 由此带来 的各种政策红利也使得杭州市服务外包产业迎来了 新的成长机遇, 逐渐呈现具有特色、具有差异化的发 展态势。

从 2009 年到 2019 年, 杭州市在这十年间里, 服 务外包产业呈现出了卓越的成长趋势。根据杭州市商 务局披露的数据显示, 2019 年全市离岸服务外包合同 执行额 71.86 亿美元, 是 2009 年离岸服务外包合同 执行额的 7.8 倍，其中 ITO 合同接包执行额为 42.68 亿美元, 为主要组成部分, 占总执行额的 $59.39 \%$ 。从 以上数据可以清晰地看出, 杭州市正在重点发展以软 件设计、网络与数字增值业务服务和电信等具有传统 优势的产业为核心的 ITO, 并以此为基础不断的扩充 自己的产业范围, 提升接收业务的层次, 逐步实现产 业规模、层次的双重飞跃。近几年, 杭州市共认定了 20 个服贸示范园区、104 家服贸示范企业以及 51 家 成长型企业, 如杭州高新区（滨江）物联网产业园、 中国 (杭州) 跨境电子商务综合试验区等 ${ }^{[2]}$ 。杭州市 的上述举措意在鼓励支持服务贸易产业发展, 促进多 市场主体形成, 以示范辐射效应为杭州市整体区域范 围内的产业发展再添生力。

杭州市服务外包产业的发展规模不断地扩大，同 时也潜伏着较多的问题。首先, 杭州市承接的服务外
包业务虽逐渐向中高端业务倾斜, 但仍有陷入 “价值 链低端锁定”陷阱的危险。且在承接业务的过程中, 与发包方之间的关系也比较被动, 在国际服务外包市 场中缺乏主动性和竞争力。其次, 杭州缺乏中高端熟 练服务外包人才, 高校学生无法充分满足熟练人才缺 口, 尤其近几年杭州房地产增值迅速，人民生活成本 日益增加, 意味着需要付出更多的人力资源成本才能 留住人才, 这明显不利于杭州市服务外包企业的发展。 第三, 缺乏健全的知识产权保护体系, 在承接服务外 包业务时常有商业信息盗用、版权侵犯的问题发生, 这样既不利于杭州服务外包企业自身自主知识产权 的保护，也不利于杭州在国际服务外包市场上诚信形 象的建立。第四, 服务外包产业相关的基础设施建设 仍需健全, 现有的基础设施没有办法充分的支撑服务 外包产业进一步发展并形成集聚效应, 再加之没有较 为良好的商业环境吸引中高端国际服务外包业务, 以 此形成恶性循环加重阻碍整个产业的发展。

\section{3. 杭州市服务外包业产业竞争力评价体系 构建}

\section{1. 评价方法的选择}

本文选取各统计数据, 基于因子分析法来进行构 建服务外包业产业竞争力的评价体系。通过由抽取出 来的各个主因子旋转后的方差贡献率作为权重后形 成综合评价函数, 对选取的地区进行计算得分排名, 由此来对区域服务外包业产业的竞争力进行分析。

\section{2. 数据的选取及说明}

本文选取长三角、珠三角、京津翼地区 9 个服务 外包示范城市 (长三角地区: 上海、苏州、南京、合 肥、杭州; 珠三角地区: 广州、深圳; 京津翼地区: 北京、天津）的原始数据为样本。借鉴前期相关理论 研究以及 “中国服务外包承接地综合评价体系”，考 虑到数据的可获取性从市场开拓、知识产权保护、人 力资源储备、商业环境四方面选取数据, 最终确定 8 项与产业相关的指标以构建服务外包业产业竞争力 评价体系 (如表 1 所示)。通过各个城市之间的比较 分析来揭示杭州市服务外包业产业发展的优势和劣 势。

表 1 服务外包产业竞争力评价体系

\begin{tabular}{|c|l|}
\hline 一级指标 & \multicolumn{1}{|c|}{ 二级指标 } \\
\hline \multirow{2}{*}{ 市场开拓 } & 货运量 X1 \\
\cline { 2 - 2 } & 出口总额 X2 \\
\hline $\begin{array}{c}\text { 知识产权 } \\
\text { 保护 }\end{array}$ & 专利授权量 X3 \\
\cline { 2 - 2 } $\begin{array}{c}\text { 人力资源 } \\
\text { 储备 }\end{array}$ & 科学研窐与经济发展经费支出 X4 等学校在校学生人数 X5 \\
\hline \multirow{3}{*}{ 商业环境 } & 政府公共预算支出 X6 \\
\cline { 2 - 2 } & 固定互联网接入用户 X7 \\
\cline { 2 - 2 } & 交通运输、仓储和邮政业生产总值 X8 \\
\hline
\end{tabular}


本文重点参考了国家统计局数据、各省市 2019 年统计年鉴、政府文件、中国服务外包网等资料，最 终确定了 9 个城市 2018 年各个指标的原始数据。

\section{4. 实证分析}

\section{1. 实证分析过程}

\subsection{1. 数据处理}

在实证分析之前, 首先利用 $\mathrm{spss} 25.0$ 软件对各指 标数据进行标准化处理, 以消除变量之间在数量级、 量纲上的影响。

\subsubsection{KMO 与 Bartlett 检验}

从大量原始变量中提取出少数具有代表性的变 量因子是运行因子分析的目的, 为达到目的需要满足 一定的前提条件, 因此在分析之前, 首先要对数据进 行 KMO 与 Bartlett 检验, 结果如表 2 所示: KMO 值 为 0.605 , 符合因子分析要求; Bartlett 球形检验近 似卡方值为 67.225 , 符合显著性水平要求。KMO 和 Bartlett 都符合效度标准, 因子分析可以有效运行, 因此可以进行下一步操作。

表 2 KMO 和 Bartlett 检验

\begin{tabular}{|l|l|r|}
\hline \multicolumn{2}{|l|}{ KMO 取样适切性量数。 } & 0.605 \\
\hline 巴特利特球形度检验 & 近似卡方 & 67.225 \\
\cline { 2 - 3 } & 自由度 & 28 \\
\cline { 2 - 3 } & 显著性 & 0 \\
\hline
\end{tabular}

\subsection{3. 因子分析}

本文为提取所有原始变量的特征值选用主成分 分析法, 将特征值大于 1 的 2 个成分作为原始 8 个指 标变量的公因子, 且得到这 2 个公因子的方差贡献率 分别为: $55.532 \%$ 和 $24.820 \%$, 总累计方差贡献率为 $80.352 \%$, 说明这 2 个公因子已经包含了原始变量中 的主要信息, 符合公因子的选取标准。通过进一步的 Varimax 方差正交旋转, 以此得到旋转后的因子载荷 矩阵, 如表 3 所示。

表 3 旋转后的因子载荷矩阵

\begin{tabular}{|l|r|r|}
\hline \multirow{2}{*}{} & \multicolumn{2}{|c|}{ 成分 } \\
\cline { 2 - 3 } & 1 & \multicolumn{1}{|c|}{2} \\
\hline 政府一般公共预算支出 & 0.908 & -0.032 \\
\hline 专利授权量 & 0.906 & 0.218 \\
\hline $\begin{array}{l}\text { 交通运输、仓储和邮政业生产 } \\
\text { 总值 }\end{array}$ & 0.881 & 0.320 \\
\hline 固定互联网接入用户 & 0.877 & -0.015 \\
\hline 科学研究与实验发展经费支出 & 0.776 & -0.231 \\
\hline 出口总额 & 0.665 & -0.489 \\
\hline
\end{tabular}

\begin{tabular}{|l|r|r|} 
普通高等学校在校学生人数 & -0.202 & 0.926 \\
\hline 货运量 & 0.405 & 0.829 \\
\hline
\end{tabular}

根据表 3 显示, 公因子 $\mathrm{F} 1$ 的成分由出口总额 $\mathrm{X} 2$, 专利授权量 X3, 科学研究与实验发展研究经费支出 X4，政府一般公共预算 X6, 互联网接入用户 X7, 交 通运输、仓储和邮政业生产总值 X8 这些因子组成, 从数量上可以判断出 $\mathrm{F} 1$ 是主要评判因子, 同时也是 一个较为综合的公因子, 反映了市场开拓、知识产权 保护以及商务环境三个方面, 故我们将 F1 命名为发 展实力因子。

公因子 F2 的成分主要由货运量 $\mathrm{X} 1$, 普通高等学 校在校学生人数 X5 这类反映市场开拓和人力资源储 备的因子组成, 这两个因子代表着社会在人才供应和 市场搭建方面给予服务外包业产业成长的支持, 故将 F2 命名为社会支持因子。

\section{2. 实证分析结果}

本文通过每个因子得分系数和原始变量的标准 化值, 采用回归法将公因子表达成变量计算的线性形 式，以此得出各个城市公因子分数。通过计算公式: 综合评价得分 $\mathrm{F}=55.498 / 80.352 \times \mathrm{F} 1+24.854 / 80.352 \times$ F2, 对 9 个城市的公共因子、综合评价得分及排名情 况并进行排名, 结果如表 4 所示。

表 49 个城市的综合评价、公共因子得分及排名情 况表

\begin{tabular}{|c|c|c|c|c|c|c|}
\hline $\begin{array}{c}\text { 城 } \\
\text { 市 }\end{array}$ & $F 1$ & $\begin{array}{c}\text { 排 } \\
\text { 名 }\end{array}$ & $F 2$ & $\begin{array}{c}\text { 排 } \\
\text { 名 }\end{array}$ & $F$ & $\begin{array}{c}\text { 排 } \\
\text { 名 }\end{array}$ \\
\hline $\begin{array}{c}\text { 上 } \\
\text { 海 }\end{array}$ & 2.26227 & 1 & 0.72861 & 2 & 1.79 & 1 \\
\hline $\begin{array}{c}\text { 广 } \\
\text { 州 }\end{array}$ & -0.1873 & 5 & 1.78372 & 1 & 0.42 & 2 \\
\hline $\begin{array}{c}\text { 北 } \\
\text { 京 }\end{array}$ & 0.58926 & 2 & -0.46 & 7 & 0.26 & 3 \\
\hline $\begin{array}{c}\text { 深 } \\
\text { 圳 }\end{array}$ & 0.31866 & 3 & -1.5058 & 9 & -0.25 & 4 \\
\hline $\begin{array}{c}\text { 天 } \\
\text { 津 }\end{array}$ & -0.4701 & 6 & 0.12625 & 5 & -0.29 & 5 \\
\hline $\begin{array}{l}\text { 杭 } \\
\text { 州 }\end{array}$ & -0.5407 & 7 & -0.1347 & 6 & -0.42 & 6 \\
\hline $\begin{array}{l}\text { 南 } \\
\text { 京 }\end{array}$ & -0.7827 & 8 & 0.38205 & 3 & -0.42 & 7 \\
\hline $\begin{array}{c}\text { 苏 } \\
\text { 州 }\end{array}$ & -0.0633 & 4 & -1.2363 & 8 & -0.43 & 8 \\
\hline $\begin{array}{l}\text { 合 } \\
\text { 肥 }\end{array}$ & -1.1262 & 9 & 0.31619 & 4 & -0.68 & 9 \\
\hline
\end{tabular}

\section{3. 杭州市竞争力分析}

由 9 个城市的公共因子、综合评价得分及排名情 况表我们可以清晰的看出, 上海、广州、北京在综合 评价得分 $\mathrm{F}$ 上排名前三, 说明这三个城市具有很强的 
服务外包业产业竞争力, 也与其直辖市和沿海发达城 市的地位相符，而杭州市排名第六，排名处于中等水 平且在得分上与前三名具有一些差距, 说明杭州的服 务外包业产业竞争力还不够显著, 对国际服务外包客 户缺乏吸引力, 仍需继续完善发展, 才能使得全市服 务外包产业蓬勃发展。

在两个公因子得分方面, 杭州市发展实力因子第 七，社会支持因子第六，都处于排名的中下游水平， 说明杭州市在市场开拓、知识产权保护、人力资源储 备、商业环境这四个方面都需要进一步提升。通过观 察综合得分排名前三的城市我们可以看出, 他们都只 在其中的一个公因子上占据优势, 这也为杭州市服务 外包业发展提供了借鉴: 实现全面健全的产业发展路 径需要不断的探索和试验, 杭州市作为服务外包示范 城市, 在一定程度上享受国家政策的倾斜, 杭州市政 府可以在政府政策支持上持续发力, 加强政府引导力 度以及资金支持, 通过营造更好的商业环境来实现服 务外包经济的快速发展。

\section{5. 结论}

\section{1. 增强杭州市服务外包业产业竞争力建议}

\subsection{1. 结合产业特色及优势, 提高承接业务 层次}

杭州市现阶段虽然还是以承接原有传统的 ITO 为主, 但也逐渐有类似动漫制作、医药研发外包等文 化创意产业逐渐萌芽, 这些创意文化产业也为承接新 型业务转移奠定了基础。为了更好的推动服务外包产 业发展, 杭州市政府和企业应当抓住机遇, 清晰准确 的了解全市产业特色和比较优势, 明确自身接包的定 位, 与周边城市错位接收业务, 实现差异化竞争。与 此同时, 为了避免处于 “微笑曲线”下沉的中间地带, 在继续加强 ITO 等传统主导产业发展的同时, 也要着 眼于 BPO、KP0 中高端外包领域, 紧跟国际市场动向, 有预见性的主动提供服务外包业务, 逐步改善提升服 务外包业务层次。

\subsection{2. 加强高校企业合作，完善人才引进体 系}

在人才吸引方面, 杭州市与长三角其余城市相比 并不具有优势: 本土培养出来的人才易于流失到周边 省市, 又无法充分吸引外来人才, 造成了巨大的人才 缺口。政府应利用地理优势加强与周边省市高校的联 动, 吸引高校来杭办学或与当地企业联动开设培训课 程, 合理设计人才培养体系, 针对服务外包产业培养 对口中高尖人才, 做到产学研相结合, 规避高等学校 偏重理论教学和企业缺乏理论支撑的通病, 达到增加 本土培养人才的目的。想要解决吸引外来人才的问题, 杭州政府需将政策措施落到实处, 优先解决本地房屋 租住和子女入学等现实问题, 再进一步控制高房价, 以及建立完善的薪资体系提升工资, 充分保障来杭工 作人员的生活和利益。

\subsection{3. 健全相关法规, 激发产业创新动力}

一方面，服务外包业务大多具有跨国性，国内的 很多法律不适用或者不完善, 国际上的适用的公约或 协议又大多不具有强制性; 另一方面, 我国服务外包 企业知识产权保护意识欠缺, 在承接业务过程中会无 意识地将自身核心知识产权泄露, 又缺乏相关法律知 识维护自身合法利益。因此为了更好的促进产业的发 展, 政府需要进一步完善我国的服务外包产业相关的 法律法规, 同时也要进一步加大宣传知识产权的保护 力度。同时引导、培训企业树立自主知识产权意识, 利用合同这一基本形式做好最基本的法律保障。有了 完善的法律体系作为保障, 才能激发产业创新动力, 产生一批又一批积极参与自主技术创新的服务外包 企业。

\subsection{4. 优化商业环境, 加强产业集群能力}

服务外包产业集群是贯穿于服务外包产业链的 始终。想要加强产业集中态势, 形成产业集聚效应, 一定要优化全市的商业环境, 形成健康、有序的商业 竞争环境。政府可以从加快搭建高水平、低成本的信 息基础设施和交通网络方面做起, 加快信息标准化建 设, 逐渐推进杭州城市整体信息化, 提高整个园区、 整个城市的承载能力和承载水平, 吸引更多的高附加 值服务外包企业来到杭州进行投资，提高产业集群能 力。

\section{REFERENCES}

[1] Website of the Ministry of Commerce of China. (2020) China's Ministry of Commerce released the development of national service outsourcing in 2019. http://sg.mofcom.gov.cn/article/jmgd/202002/2020 0202937918.shtml.

[2] Hangzhou Bureau of Commerce. (2020) Innovation and cultivation of market players in service trade Hangzhou has identified a number of service trade demonstration zones. http://sww.hangzhou.gov.cn/art/2020/10/14/art_155 1496_58884833.html.

[3] HUANG, H. WU, S. (2019) Analysis on the current situation and countermeasures of International service outsourcing in China. Foreign Economic and Trade Practice, 2019(12):86-89.

[4] GU, L. CHEN, Y. The influence mechanism of "One Belt And One Road" international service outsourcing on inclusive growth -- a case study of Zhejiang province. (2019) Business economics Research, 2019(02):122-125.

[5] WANG, G. Research on competitiveness Evaluation of Service outsourcing Industry in Beijing, Tianjin and Hebei. (2016) Journal of Hubei University of Science and Technology, 36(12):25-29. 